\title{
A teoria da dependência na América Latina
}

\section{LUIZ TOLEDO MACHADO}

A RIGOR, NÃO EXISTE uma teoria da dependência, mas simplesmente a dependência dentro do sistema internacional de relações de força e poder. O que se pretendeu chamar de teoria da dependência é uma obviedade histórica; uma tentativa de nova versão do modelo neocolonial, já descrito e conhecido desde o século XIX quando, então, o sistema político das nações hegemônicas impôs às ex-colônias um novo modelo sócio-econômico e político de exploração em nome do liberalismo triunfante.

O que importa, nesta altura, é examinar o novo modelo colonial, quando o antigo da divisão internacional do trabalho e da distribuição da renda internacional se esgotou. O capitalismo mundializado passou a aplicar novos mecanismos de apropriação do excedente periférico pela via das empresas transnacionais e do sistema financeiro especulativo, aliando-se às burguesias emergentes locais.

As discussões dos anos 50 e 60 acerca do desenvolvimento/subdesenvolvimento giraram em torno da participação do capital estrangeiro nas economias periféricas: se os ingressos externos dinamizariam as economias, ou ao revés, constituiriam obstáculo ao crescimento dos capitalismos locais. Essa colocação levava ao círculo vicioso de Gunnar Myrdal. Se de um lado as economias subdesenvolvidas careciam de investimentos que não eram atendidos pela iniciativa privada para a ampliação da sua capacidade produtiva em razão da ausência histórica de acumulação interna, dos reduzidos salários e da crônica exclusão do mercado da maioria populacional, do outro a política de importar bens e serviços, contrair empréstimos para a criação de infra-estrutura e modernização do equipamento e atrair o capital estrangeiro levava à maior descapitalização e ao endividamento crescente pela via dos juros a serem pagos, das importações de matérias-primas e do repatriamento do capital internacional estabelecido, o que agravava a dependência externa.

O que não se aprofundava era o grau possível de determinação dos Estados nacionais no desenvolvimento econômico, os limites do seu cam- 
po de ação para exercer papel decisório nos investimentos e no controle das repatriações a curto prazo, de maneira a concentrar nos países parte do excedente econômico.

A história econômica e financeira dos países da América Latina é a do crônico e crescente endividamento externo e de maior submissão ao capital forâneo. O resultado aí está na total internacionalização tanto do Estado como do incipiente setor privado, o que faz pensar que dentro do atual ordenamento internacional a nação está desaparecendo como categoria histórica.

Desde o início, a dependência está nas relações internacionais de domínio e submissão no sistema de interdependências. Não há, pois, mesmo teoricamente, como passar da teoria econômica do subdesenvolvimento para uma teoria da dependência, uma vez que a dependência antecede o subdesenvolvimento. Essa constatação óbvia não elide a importância e o significado dos estudos que buscam explicar o desenvolvimento/subdesenvolvimento pelo processo histórico, pela interpretação econômica segundo as leis do próprio capitalismo, do marxismo ou do estruturalismo.

No campo das Ciências Sociais, não cabe a sociologia da dependência como disciplina particular acadêmica, pois, como argumenta Luiz Pereira, "não é possível conceber o desenvolvimento (e o subdesenvolvimento) em geral a não ser como uma abstração: a de um processo de mudança progressiva. Todavia, dada que essa mudança é histórica, impõe-se pensá-la em termos de distintas estruturas de historicidade, das quais procuram dar conta os conceitos dos distintos modos de produção. (...) Em segundo lugar, não há como admitir a própria existência da sociologia como disciplina distinta dentre as academicamente chamadas ciências humanas ou sociais, distinta, por exemplo, de uma ciência econômica e de uma ciência política. Mesmo estas últimas só têm existência, respectivamente, enquanto sinteses orientadas para a dimensão econômica e para a dimensão política, à medida em que essas dimensões são constitutivas, enquanto conteúdos distintos, do conjunto articulado das práticas sociais estruturadas" (1).

No pós-guerra, a questão nacional na América Latina teve como fulcro a problemática do desenvolvimento/subdesenvolvimento e as suas diferentes interpretações. No Ilpes (órgão da Cepal - Comissão Econômica para a América Latina e Caribe) como no Ceso (Centro de Estudios SocioEconómicos da Universidade do Chile), produziram-se as primeiras tentativas de elaboração de uma teoria do subdesenvolvimento. Os esforços consistiram na atualização dos estudos sobre o capitalismo como categoria econômica histórica, o neocolonialismo e a expansão do capitalismo cen- 
tral na periferia. Seu maior mérito foi o de colocar a economia, antes tratada como matéria autônoma, relacionada com o processo de dominação internacional, no quadro das Ciências Políticas. Para tanto, cruzaram-se a corrente neomarxista norte-americana e a estruturalista da Cepal: daí decorreu a noção da dependência, extraída da assimetria das relações econômicas internacionais, da política das nações hegemônicas em cada período histórico, dos seus modelos de exploração econômico-financeira e da multidimensionalidade na criação e alocação de recursos, vale dizer, da apropriação do excedente econômico (2).

Tanto na economia clássica quanto no marxismo, o problema do excedente e sua utilização está no núcleo do crescimento econômico. Gunder Frank, um dos expoentes da teoria do desenvolvimento/subdesenvolvimento, considera que "o processo da acumulação do capital é um dos motores principais (senão mesmo o principal) da história moderna". Daí que o subdesenvolvimento implica a "análise das relações dependentes de produção e de troca no interior do processo mundial de acumulação de capital (3).

Também o substantivo subdesenvolvimento tem sido objeto de crítica por inadequação ao seu significado. Charles Bettlheim contesta a sua interpretação linear ligada aos modos de produção clássicos da Europa, tratando o subdesenvolvimento como um processo particular em relação aos países avançados, que não sofreram exploração econômica, dominação política e cuja trajetória não pode ser considerada segundo os estágios paradigmáticos do capitalismo central.

O jurista e sociólogo Pinto Ferreira (4), num dos raros trabalhos considerados excelentes quanto à aplicação dos métodos sociológicos na análise do desenvolvimento/subdesenvolvimento, desloca a problemática da dependência para o processo de mudança social.

$\mathrm{Na}$ realidade, as mudanças nas estruturas sociais não ocorrem de maneira espontânea e isolada, mas em contextos historicamente definidos, extra-sociológicos. A análise do subdesenvolvimento requer que se evite a segmentação das disciplinas das Ciências Sociais por mera acomodação acadêmica. Mesmo George Balandier evitou estabelecer uma teoria da dependência, tratando simplesmente da sociologia das regiões subdesenvolvidas.

No caso, o campo natural da sociologia limita-se ao estudo das mudanças sociais, das estratificações e relações de classes e grupos no interior das sociedades subdesenvolvidas. 
A dependência, entendida como condição histórica, como estado ou caráter de sujeição, subordinação, ou como efeito dependente de causa, apresenta sentido tão genérico que não pode ser reduzido a teoria, tomada esta como mero conhecimento especulativo, ou ainda como doutrina ou sistema geral. O processo econômico díspare, que produziu a metáfora da abertura da tesoura, pode ser examinado de maneira sistemática em suas relações íntimas com a política internacional e interna dos países subdesenvolvidos, em diferentes períodos da evolução das economias centrais.

O sistema capitalista, que gerou a acumulação centralizada do capital dando origem ao crescimento conjugado com o avanço tecnológico nos países de economia desenvolvida, ao revés, produziu a estagnação da periferia durante vários séculos a despeito dos esforços industrializantes. O que arbitrariamente foi tratado por alguns autores como teoria da dependência bem pode ser capitulado no Direito Internacional, nas relações históricas de exploração entre povos e nações. As relações de subordinação e condicionamento aos pólos autônomos da economia mundial inscrevem-se no sistema da interdependência mundial.

Sobre a óptica filosófica e moral, a dependência inclui-se no discurso acerca das teorias das desigualdades fundamentais, aplicadas às relações internacionais entre o centro e a periferia, legitimadas em nome da civilização e aceitas pela servidão voluntária das lideranças subdesenvolvidas. Samir Amin tratou com resignada displicência a teoria heterodoxa da dependência, uma vez que o seu conceito de desenvolvimento é o da economia nacional promovido pelo Estado, conforme as lições de List e Hamilton.

Na verdade, a interpretação natural do desenvolvimento/subdesenvolvimento envolve conceitos derivados do marxismo-leninismo pela via francesa e da versão estruturalista dos estudos da Cepal, que concebeu por algumas vertentes o estudo do atraso e a dependência da região, bem como as alternativas de crescimento, consoante as perspectivas ideológicas dos seus tratadistas. E não poderia ser de outro modo, pois a teoria sociológica norte-americana liberal e utilitarista estava voltada para o princípio da estabilidade e não da mudança ou ruptura, pouco ou nada podendo contribuir para o esclarecimento do subdesenvolvimento. O não-reconhecimento da questão nacional como chave para o desenvolvimento redundou no que aconteceu no Brasil e demais países da América Latina, a industrialização dependente conforme Celso Furtado, ou ainda associada, em que os grupos oligopolistas transnacionais assimilaram o setor econômico nacional e dominaram o mercado. 
Recorda-se que, em novembro de 1954, no Encontro dos Ministros da Fazenda ou da Economia da América Latina - IV Sessão Extraordinária do Conselho Interamericano da OEA -, realizado no Rio de Janeiro, cuja agenda foi preparada pela Cepal, oficializou-se a tese dos investidores norte-americanos de que o crescimento econômico da região só seria possível com a presença dos oligopólios internacionais, na forma de investimentos diretos ou em associação com os incipientes capitais privados locais.

O Informe Preliminar da Secretaria Executiva da Cepal assim justificava a necessidade do capital estrangeiro: "A América Latina vem experimentando um ritmo de crescimento muito alto durante os últimos anos. A renda média por habitante subiu de $3,3 \%$, anualmente, no período de 1945 52 em comparação com a taxa de $1,9 \%$ registrada no crescimento histórico dos Estados Unidos. Se uma taxa como essa fosse mantida com persistência, os países latino-americanos poderiam melhorar em 100\% dentro de 21 anos o seu nível de vida atual. Mas, infelizmente, os fatores que impulsionaram esse crescimento foram fatores extraordinários e não parecem se repetir agora".

Para a manutenção do crescimento econômico, o documento considerava como "elemento primordial a inversão de capital estrangeiro, a fim de romper o conhecido círculo vicioso de uma renda baixa que não permite aumentar a capitalização, e de uma capitalização que é insuficiente devido à renda precária. (...) O desenvolvimento econômico depende em grande proporção da iniciativa privada. É em geral, na América Latina, o reconhecimento desse conceito, até mesmo nos países que se têm caracterizado por certas intervenções estatais que entravam a livre iniciativa. (...) Quando se fala de iniciativa privada nos países interessados no desenvolvimento latino-americano, pensa-se sobretudo na iniciativa de empresas estrangeiras e, algumas vezes, da sua possível combinação com o capital privado interno" (5).

Essas diretrizes, que tiveram o apoio da maioria do empresariado local, só foram contestadas nos círculos intelectuais, que admitiam o capital estrangeiro dentro de uma política planejada de desenvolvimento nacional, dirigida por governos independentes e envolvendo a presença do Estado, por razões óbvias, na exploração dos setores estratégicos.

Os economistas Emmanuel Arghiri e Samir Amin, respectivamente, em L'échange inégal e L'accumulation à l'chelle mondiale, contribuíram decisivamente para a compreensão do desenvolvimento/subdesenvolvimento, revolucionando os antigos conceitos deterministas de extração etnocêntrica, que permitiam considerar o subdesenvolvimento na sua concepção isola- 
da, como objeto de teoria própria e específica. O funcionamento do sistema capitalista, desde o início da era moderna foi caracteristicamente macroespacial, de maneira que o subdesenvolvimento se inscreve na sua lógica expansionista.

As economias centrais, depois de consolidarem seu sistema econômico nacional de maneira autocentrada, impulsionadas pelo dinamismo da reprodução do capital, ampliaram em escala mundial o seu espaço vital (Lebesraun), modelando assim a natureza extrovertida da economia periférica. Posteriormente, a partir do último pós-guerra, em decorrência da superacumulação de capital e das vantagens comparativas quanto ao emprego da mão-de-obra, realizaram o deslocamento da produção e do capital do centro para os países subdesenvolvidos, bloqueando o desenvolvimento das economias nacionais emergentes e superpondo-se aos próprios Estados nacionais, submetidos por razões óbvias aos seus interesses.

Portanto, não se pode considerar seriamente como teoria o processo vinculado centro-periferia, senão no campo das relações políticas e econômicas internacionais.

A taxonomia das Ciências Sociais na América Latina é sumamente arbitrária, nem sempre correspondendo ou esclarecendo o seu conteúdo objectual. As classificações ideológicas, econômicas e políticas transpostas carecem de adequação às realidades nacionais, constituindo mais uma combinação heteróclita de idéias, fragmentos ideológicos e conceitos deslocados, que não guardam coerência interna com as ideologias e disciplinas sistematizadas no exterior. Quando tentam recriar ou nomear situações específicas, adotam neologismos assistemáticos de confusa conceituação.

Gunnar Myrdal, marco do pensamento analítico do subdesenvolvimento, nas suas conferências do Cairo em outubro de 1955, ao estudar "o mecanismo das desigualdades econômicas nacionais e internacionais", teve o honesto cuidado de designá-lo como teoria econômica, considerando-a um segmento da cultura geral. Mesmo diante da necessidade de uma teoria econômica geral, indispensável ao trabalho científico, alertava para o risco do apriorismo: "Se a teoria for estabelecida a priori, por outro lado é princípio básico da ciência que os fatos são soberanos. Em outras palavras, a teoria nunca é mais do que uma hipótese"

Em princípio, Gunnar Myrdal situa o problema da desigualdade internacional no plano da consciência pública: "Quando fatos relacionados com as desigualdades econômicas internacionais e sua tendência a crescer são confrontados com a consciência pública nas nações mais ricas e com a 
teoria econômica que se formou no ambiente cultural desses países, as discordâncias tanto nas esferas morais quanto nas intelectuais tornam-se evidentes. Dessas, as discordâncias de ordem moral, sem dúvida, são as mais importantes" (6).

Rousseau, no Discurso sobre a origem da desigualdade, já havia colocado a questão em termos de consciência moral (7).

A contribuição mais conhecida de Gunnar Myrdal para o desenvolvimento/subdesenvolvimento está no princípio do círculo vicioso, que ele denomina "causação circular e acumulativa”, pelo qual " um fator negativo é, simultaneamente, causa e efeito de outros fatores negativos". Myrdal cita com propósito explicativo a Bíblia (São Matheus, XXV: 29, Cf. Xlll): "A quem tem será dado e terá abundância, mas de quem não tem será tomado mesmo o que não tem”. Em última instância, os países ricos reproduzem a riqueza e os pobres reproduzem a pobreza.

O sistema capitalista em sua expansão mundial produziu os padrões de desigualdade tanto em sua etapa mercantilista como monopolista industrial e financeira até a atual globalização. O problema da apropriação, concentração e centralização do excedente econômico é o ponto crucial do desenvolvimento/subdesenvolvimento e, portanto, do sistema de interdependência mundial. Assim, importa considerar os tipos de relações e as formas de apropriação dos recursos produtivos da periferia pelo centro ao longo dos últimos cinco séculos.

A dependência política e econômica continuada poderá esclarecer em parte o subdesenvolvimento do mundo latino-americano e afro-asiático (a despeito da defasagem entre ambos os processos), condicionados aos mecanismos de apropriação e acumulação do excedente econômico, pelo crônico endividamento externo, pelas relações de trocas desiguais, pela dominação do capital financeiro e bancário, com a complacência e conivência inicialmente das classes senhoriais, das oligarquias agroextrativistas exportadoras e, posteriormente, dos agentes da subeconomia industrial, os quais tradicionalmente exerceram o controle do poder estatal.

O crescimento econômico não depende simplesmente das formas denominadas institucionais e técnicas da produção do excedente econômico e no modo de sua utilização, mas implica basicamente a política econômica geral dos Estados no sistema das interdependências. Quanto maior for o grau da subordinação externa, menor será sua possibilidade de crescimento. A questão nacional coloca-se aí como chave-mestra para o desenvolvimento e bem-estar social. Pierre Vilar assim explica as desigualdades 
de desenvolvimento nas sociedades prometéicas da Europa: "Em toda conjuntura geral, os diferentes países reagem de maneira diversa: daí as desigualdades de desenvolvimento que, finalmente, fazem a história” (8).

A América Latina experimentou ao longo dos séculos um crescimento vegetativo à sombra da Europa e dos Estados Unidos, situando-se praticamente fora da própria historicidade do Ocidente. Na forma da sua inserção aos domínios ultramarinos europeus está a origem do subdesenvolvimento e da dependência, que se prolongaram no tempo. A ocidentalização desses espaços iniciou-se com o sistema colonial, confrontando o modo de produção agroextrativista com os padrões de produção, acumulação de capital, práticas e teorias mercantis e, posteriormente, monopolistas-industriais. Daí que o capitalismo tardio e dependente latino-americano decorreu originalmente de contingência histórica.

A maior parte dos estudos ocidentais acerca do subdesenvolvimento toma como modelo a teoria clássica do capitalismo fundada na iniciativa privada e no mercado em sua função competitiva. O receio de contestar a matriz conceitual do sistema anglo-saxônico conduziu os economistas em geral à tese que justifica o subdesenvolvimento pela inexistência da situação pré-capitalista das economias periféricas, o que teria impedido a acumulação interna necessária ao arranco industrial. Ora, o subdesenvolvimento por si só não pode ser explicado unilateralmente pela ausência da acumulação pré-capitalista, mesmo porque esses países não passaram pelo mesmo processo histórico europeu, nem poderiam ter realizado a revolução industrial nas circunstâncias da Inglaterra nos séculos 18 e 19 e dos demais países que a realizaram posteriormente.

A realidade histórica dos países latino-americanos (também dos africanos e do Sudeste asiático) evidencia que a repetição do caminho seguido pelas potências industriais não é válido como modelo ou orientação, nem poderá ser repetido por razões óbvias. Os processos diferenciados estão a indicar que o modelo ortodoxamente privativista liberal não serve mesmo como referência ao estudo comparativo para os países que se encontram atualmente em situação de subdesenvolvimento e dependência.

Os mecanismos de apropriação colonial e imperialista do excedente econômico mundial estão na origem da automaticidade do crescimento baseado na acumulação privada e estatal das potências hegemônicas. $\mathrm{Na}$ periferia, a acumulação privada não responde pelo crescimento econômico, primeiramente porque as empresas internacionais e transnacionais apenas realizam a apropriação do excedente nos países dessa região e, em segundo lugar, porque o que resta localmente é apropriado pelo setor priva- 
do, o que, no caso, não significa crescimento econômico nem distribuição de renda em favor do mercado, pois transforma-se em excedente improdutivo em virtude do consumo conspícuo de classe, da mentalidade suntuária das oligarquias e do empresariado subdesenvolvido.

A própria industrialização incipiente da América Latina deve-se não apenas ao Estado-propulsor da economia, mas ao próprio crescimento vegetativo das populações urbanas. A ênfase do liberalismo no desenvolvimento privativista não funciona quando se trata de países sem antecedentes de acumulação interna de capital. Henry Wallich, comentando a teoria do desenvolvimento de Schumpeter e sua tentativa de aplicação aos países subdesenvolvidos, observa: "É bastante óbvio que a teoria de Schumpeter não se aplica aos países menos desenvolvidos. $\mathrm{O}$ empresariado não é a força propulsora, a inovação não é o processo mais característico e o enriquecimento privado não é o objetivo predominante (...) A constatação de que o empresário não constitui a principal força de propulsão do desenvolvimento dos países menos adiantados não significa naturalmente negar que representa certo papel. Trata-se, no entanto, de papel secundário (...) Quem são, pois, os protagonistas do processo de desenvolvimento? Na maioria dos países menos desenvolvidos, o processo atual de desenvolvimento parece ser predominantemente social, nacional e também nacionalista” (9). Para o autor, o governo é o "agente mais visível e ativo do desenvolvimento", o que não significa que se trate de regime socialista, pois sempre é necessária a existência de um setor privado, voltado para os bens de consumo, pois o mercado é o principal instrumento produtor do excedente econômico. Porém, o controle do excedente e de sua utilização só poderá ser realizado de maneira racional, em benefício da coletividade, pela propriedade pública. Curiosamente, o papel do Estado ou sua definição como agente principal do desenvolvimento e sua função controladora e regulamentadora no desenvolvimento, mesmo quando associado às corporações transnacionais, não foi aprofundado nos estudos sobre a dependência.

As caracterizações do subdesenvolvimento, embora convergentes para pontos comuns, diferem quanto aos mecanismos institucionais e técnicos da produção do excedente e sua utilização. Ragnar Nurkse trata da formação do capital nas regiões subdesenvolvidas, enfatizando no plano internacional a problemática dos investimentos privados externos que, durante largo tempo, mesmo depois da Independência na América Latina, continuaram o modelo colonial dirigido para o setor agroextrativista exportador em função das necessidades dos países industriais. Essa tendência, ainda predominante na maior parte da América Latina e da África, obstou a 
formação do mercado interno e do capital necessários à industrialização que, em alguns países, a exemplo do Brasil, teve início com os investimentos estatais. Essa política - segundo o autor - "contribui para explicar a observação corrente de que a poupança interna nos países subdesenvolvidos tende a ser utilizada de forma improdutiva" (10).

Será importante observar, quanto ao papel inibidor do capital estrangeiro oligopolizado na América Latina, que alguns países, a exemplo do Brasil, só puderam dar início efetivo e sistemático à industrialização durante a Grande Depressão dos anos 30, no período de retração do capital privado estrangeiro. Alguns governos, diante do impacto da crise no setor primário-exportador, reestruturaram a economia atuando diretamente na promoção do mercado interno, anteriormente submetido às importações de consumo. Para tanto, procuraram criar a infra-estrutura física necessária para o arranco inicial por meio de empresas públicas nos setores estratégicos, que chegaram a responder por $60 \%$ do PIB, e de fortes estímulos à iniciativa privada nacional.

Terminada a Segunda Grande Guerra, os capitais externos oligopolistas redirecionaram-se para o mercado interno dos países subdesenvolvidos, transferindo parte de suas empresas para a periferia (a exemplo da indústria automotiva, farmacêutica e demais), absorvendo o emergente setor industrial nacional. Embora não se tenha formulado uma teoria possível do desenvolvimento da periferia, no caso da América Latina, a teoria do sistema econômico nacional de Friedrich List e a experiência do new deal de Roosevelt trouxeram inegável contribuição intelectual. O Estado subdesenvolvido colocara-se no centro das constelações totais do desenvolvimento.

Gunder Frank, seguiu as pegadas de Paul A. Baran, que marcou os estudos sobre o subdesenvolvimento/desenvolvimento desde as suas conferências na Universidade de Oxford, em 1953, posteriormente ampliadas no livro A economia politica do desenvolvimento (1957). A posição teórica de Baran é indubitavelmente nacionalista ao tratar tanto das raízes do subdesenvolvimento como das suas diferentes morfologia. Para ele, a relação antitética entre o capitalismo central e as regiões atrasadas produziu o conceito de subdesenvolvimento. Sua tese está nucleada na expropriação - apropriação do excedente econômico -, que também orienta as de Gunder Frank: a polarização contraditória metrópole-colônia como chave da dependência. As relações de dependência seriam melhor tratadas do ponto de vista histórico convencional como relações coloniais, neocoloniais e imperialistas, pois foram regidas por estatutos específicos, caracterizando matéria 
geopolítica, já que a relação maior não está rigorosamente nos modos de produção internos, mas nas relações dos poderes hegemônicos regionais e internacionais com os países de estrutura econômica e política submetida à expropriação externa. Uma dura crítica marxista ortodoxa à tese de Gunder Frank foi produzida no Brasil num ensaio de Luiz Alfredo Galvão, partindo das ressalvas de Giovani Arrighi (11).

Num retrospecto da evolução das suas interpretações, Gunder Frank procura explicar o subdesenvolvimento/dependência. No prefácio de Capitalismo e dependência na América Latina, datado de julho de 1965, reclama a elaboração de uma teoria explicativa do desenvolvimento contraditório no sistema capitalista mundial integrado, que gera a um só tempo o desenvolvimento econômico e o subdesenvolvimento em âmbito mundial, regional, nacional e local. No seu segundo livro, América Latina: desenvolvimento ou revolução, também publicado nos anos 60 , colocava essas duas alternativas, reafirmadas por Hélio Jaguaribe em Crises e alternativas da América Latina: reforma ou revolução, livro editado na Argentina em 1972, contendo no segundo capítulo uma analise estrutural da economia latinoamericana com destaque para a estagnação e desnacionalização tanto econômica quanto cultural e político-militar. Alternativas que, afinal, se realizaram em sentido inverso: antidesenvolvimento e contra-revolução.

Enquanto a tese central de Gunder Frank sobre o subdesenvolvimento era a das relações externas de troca conectadas com o mercado interno e a acumulação de capital, a de Hélio Jaguaribe centrava-se no dualismo das sociedades latino-americanas. Formulava as indagações seguintes: Por que as sociedades latino-americanas, depois da sua Independência até 1930, não puderam alcançar o seu desenvolvimento nacional? Por que esses países, desde o final da Segunda Guerra Mundial e, ao longo de mais de 20 anos de compromissos deliberados para alcançar um desenvolvimento nacional auto-sustentado, se mostraram incapazes de chegar a tal meta? Propondo algumas hipóteses, salientava num primeiro plano que essas sociedades, "desde sua Independência até as primeiras décadas do século XX, foram levadas a converter-se em sociedades dualistas, nas quais a elevação ao seu ponto ótimo dos objetivos da elite não era compatível com os interesses da massa, o que impediu a integração social dos países em questão e provocou o estabelecimento de um regime social (quer dizer, de um regime de valores, participação, poder e propriedade) que não valia para o seu desenvolvimento nacional" (12).

Como se percebe, a questão do subdesenvolvimento/dependência aparece diagnosticada pela maioria dos autores que trataram do assunto, 
porém divergem quanto ao seu móvel, isto é quanto à direção da determinação. Giovani Arrighi, ao fazer a crítica da tese de Gunder Frank, adota a hipótese de ser o "modo de produção interno" que determina as "relações externas de troca", e não o contrário. O equívoco de Arrighi está no fato de considerar os países da América Latina dotados de determinação interna e de uma tradição econômica de modos de produção semelhantes aos da Europa. Rui Mauro Marini, na Dialética da dependência, retomou o princípio determinante de Gunder Frank das relações externas de troca, de onde se conclui que somente a ruptura com o sistema internacional poderia propiciar o desenvolvimento em termos de auto-suficiência.

Celso Furtado, desde os ensaios publicados entre 1952 e 1960, reunidos no livro Desenvolvimento e subdesenvolvimento (1961), trata do tema como Teoria politica do desenvolvimento econômico, título de seu segundo livro sobre a matéria, no qual assinala que uma teoria do desenvolvimento deve se ater ao processo de acumulação de capital dentro de uma visão histórica: "A acumulação de capital tem sua origem no fato de observação corrente de que toda coletividade humana, mesmo nos mais rudimentares níveis de divisão do trabalho, é capaz de criar um excedente, isto é, de produzir mais do que o necessário à sobrevivência dos seus membros. (...) A forma de utilização do excedente de produção e a posição social do grupo que dele se apropria constituem elementos básicos do processo social que engendra o desenvolvimento". Quanto ao subdesenvolvimento, considera suas características estruturais, tomando a palavra estrutura na acepção de François Perroux, que entende proporções e relações que caracterizam um conjunto econômico localizado dentro do tempo e do espaço: "A tomada de consciência do desenvolvimento", do ponto de vista de uma economia nacional, apresenta-se "como um processo de modificação nas estruturas e como uma expansão do fluxo da renda real por unidade do fator trabalho" (13).

Em A hegemonia dos Estados Unidos e o subdesenvolvimento da América Latina, publicado em 1973, Celso Furtado retoma a tese do imperialismo mundial e, notadamente regional, dos EUA nas suas relações com os países latino-americanos, admitindo o seu declínio hegemônico e apontado para uma nova ordem mundial policêntrica. Em A nova dependência. Dívida externa e monetarismo (1982), avança para a análise da transnacionalização econômica e financeira, vinculada ao monetarismo, o novo modelo internacional de dependência, que passou a chamar-se globalização. Nessa fase, a dependência foi levada à uma situação limite de total ocupação do aparelho produtivo público e privado, dos mercados e das finanças, provocando crises locais jamais conhecidas e, por razões decorrentes da sua 
própria estrutura global, ao colapso do sistema financeiro anunciado nos elos mais fracos do sistema: Sudeste asiático, Leste europeu e América Latina, notadamente México, Brasil e Argentina, que mais avançaram na industrialização internacionalizada.

A problemática da industrialização associada ao setor privado quanto aos seus resultados internos nas economias latino-americanas revela alguns aspectos já conhecidos, que cabem ser reiterados. Esse tipo de desenvolvimento inseriu as economias latino-americanas no mercado mundial de forma perversa e distorcida, particularmente a brasileira. Restringiu-se a setores e áreas privilegiadas da economia nacional, mercê de novas tecnologias, de maneira a não integrá-la, mas, ao contrário, agravando os desníveis regionais. A produção de bens de capital urgentemente requisitada para o reequipamento industrial ficou incompleta uma vez que o alvo das corporações multinacionais, operando com subsídios especiais, era o mercado conspícuo, de luxo, a exemplo da indústria automotiva, limitado a reduzida parcela populacional. De outra parte, deu início ao processo de internacionalização da economia, que se desdobrou na absorção das indústrias nacionais em setores decisivos, como o de alimento, químico-farmacêutico, entre outros. Em fase ulterior, tal processo avançaria até os setores estratégicos da economia, nos quais operavam com sucesso as empresas públicas.

O atributo tecnológico do subdesenvolvimento costuma ser apontado com certo destaque nos estudos sobre a matéria. O mito da importação tecnológica como queima de etapas no processo de desenvolvimento foi largamente usado nos meios empresariais para justificar o ingresso dos investimentos diretos estrangeiros. Meir Merhav refuta o argumento de que o desenvolvimento "consiste principalmente no transplante de uma tecnologia avançada numa economia atrasada, que é incapaz de produzi-la endogenamente, como resultado do seu próprio processo evolutivo. A adoção dessas técnicas alienígenas só pode ter lugar através da importação do equipamento que a incorpora. Essa maquinaria tornou-se historicamente adaptada às proporções de fatores e às escalas de produção apropriadas aos tamanhos dos mercados e ao grau de especialização de seus países de origem. Quando ela é introduzida num país subdesenvolvido, com baixo nível inicial de demanda agregada, por definição a disparidade entre as escalas de produção para as quais a tecnologia foi criada e a extensão dos mercados produz, num estágio prematuro de crescimento, uma estrutura industrial em que é tecnicamente inevitável a dominação dos monopólios" (14).

Maria Conceição Tavares, num livro clássico, Da substituição de importações ao capitalismo financeiro, critica as teorias da dependência, assinalando o seu "fracasso como marco analítico para interpretar esse tipo de 
mudanças do capitalismo central e das formas alternativas da integração da periferia, que não pode, pois, ser contornado mediante uma queveile d'écoles entre os chamados estruturalistas cepalinos de um lado e os neomarxistas do outro". Reconhece que "o processo de acumulação teria de ser o núcleo central de uma análise teórica desse tipo, porque define e determina o movimento profundo do capitalismo e, em conseqüência, é o lugar privilegiado das contradições econômicas e sociais. Os esforços empreendidos - afirma têm sido insuficientes, tanto no recorte estritamente econômico como no plano da análise sócio-política, e a maioria deles não contempla a necessidade de convergência das análises para um problema central, a saber: que o caráter contraditório do processo de expansão capitalista não pode ser apreendido em suas dimensões mais relevantes sem passar pelo esclarecimento do papel do Estado como mediador dessas contradições"(15).

Não obstante, não se pode desconhecer a importância da Cepal quanto às discussões acerca de um modelo particular de desenvolvimento e à sua posição crítica ao monetarismo. O pensamento básico da Cepal (Instituto financiado pela ONU) aparece pelo menos em dois livros de Raul Prebisch: El desarrollo económico de la América Latina y algunos de sus principales problemas e em $O$ pensamento da Cepal (1968), edição comemorativa dos 20 anos da instituição. Recentemente foi editado, na Revista da Cepal (1998), um ensaio intitulado Una sintesis de la propuesta de la Cepal, recordando a sua posição nos anos anteriores ao aparecimento do chamado Consenso de Washington, solução monetarista ortodoxa de apoio ao FMIBird.

Na realidade, as economias latino-americanas não chegaram a se firmar ou a concluir o ciclo das economias nacionais, encontrando-se, portanto, na situação de presas inermes do modelo transnacional das corporações e finanças. Raul Prebisch atribui o subdesenvolvimento às relações centroperiferia caracterizadas por constante deterioração das trocas, do que resulta a concentração de renda em nível mundial, enfim, a mundialização do capital inviabilizando todos os esforços de superação do subdesenvolvimento.

Para as análises sobre o subdesenvolvimento, foram indispensáveis a contribuição direta do economista neokeynesiano Michal Kalecky e a literatura acerca do imperialismo de Lenine, Hilferding e John Hobson (Imperialism, a study, 1902) ao lado de Colin Clark (The conditions of economic progress, 1938) e de Joan V. Robson (Essays in the theory of economic growth, 1962) (16). 
Como se observa, o centro da problemática do subdesenvolvimento foi colocado pela maioria dos economistas em termos de acumulação do excedente/investimentos, ocupando o Estado um papel secundário no direcionamento da economia, que era deixada ao arbítrio do capital estrangeiro, ou mesmo do capital nacional em função da maximização do lucro. Esse foi um dos pontos mais controversos do processo da industrialização internacionalizada da América Latina

A admissão irrestrita desse capital e a sua integração estrutural nas economias resultou na industrialização restrita que acabou por absorver as nascentes empresas nacionais impondo o seu paradigma mundial, tal como aconteceu, a partir de 1955 e, particularmente, desde os anos 80 que precederam, neste final de século, a total transformação dessas economias em subsistemas periféricos da globalização.

Nos anos de maior projeção das teses da Cepal, a questão nacional na América Latina estava espremida pela bipolaridade no confronto comunismo e anticomunismo, conforme colocação hemisférica e global da política dos EUA. As iniciativas estatais na economia eram consideradas pela ortodoxia monetarista como subproduto derivado do marxismo soviético. Movia-se na imprensa, na política e nos meios empresariais verdadeira guerra contra as empresas públicas, notadamente dos setores estratégicos (energético, em particular o petrolífero, de comunicação, transporte, e os relacionados com a exploração das riquezas minerais), os mais cobiçados pelos monopólios internacionais.

A Cepal não chegou a estabelecer um projeto de desenvolvimento, limitando-se a examinar as razões do desenvolvimento/subdesenvolvimento, a economia de substituição de importação, o modelo associado de desenvolvimento e a sua transição para o capitalismo financeiro. Chegou, no entanto, a acreditar, em dado momento, que alguns países mais desenvolvidos da América Latina, como o Brasil, a Argentina, o México e o Chile ostentavam condições de fechar o ciclo da industrialização com a participação do capital estrangeiro, para transitarem da economia de substituição de importações para a de produção de bens de capital e de materiais estratégicos.

Nos dois últimos decênios, a idéia de uma estratégia para o projeto nacional nos países latino-americanos foi abandonada diante do fenômeno da mundialização contraditória e excludente do capitalismo. Diante do seu impacto destrutivo nas economias periféricas, concomitantemente aos resultados da crise sistêmica irreversível da nova ordem econômica mundial, porém, a questão do projeto nacional retornou com indiscutível atualidade. 
Notas

1 Pereira, Luiz. Capitalismo. Notas teóricas. São Paulo, Duas Cidades, 1977, p. 67-68.

2 Ver Baran, A. Paul. Economia politica do desenvolvimento, $4^{\text {a }}$ ed. Rio de Janeiro, Zahar, 1977, p. 74 e ss., nas quais distingue as variantes do conceito de excedente econômico.

3 Ver Frank, Gunder. Acumulação mundial 1492-1789e Acumulação dependente e subdesenvolvimento.

4 Ferreira, Pinto. Sociologia do desenvolvimento. São Paulo, Revista dos Tribunais, 1993 , p. 39 e ss.

5 A cooperação internacional na politica de desenvolvimento latino-americana. Rio de Janeiro, edição das Nações Unidas, trad., out. 1954, p. 5 e ss.

6 Myrdal, Gunnar, op.cit., p. 31-33.

7 Ver Rousseau, Jean-Jacques. Discurso sobre a origem da desigualdade. In: $O$ pensamento vivo de Rousseau, apresentação de Romain Rolland, trad. de J. Cruz Costa, Martins/Edusp, 1975.

8 Vilar, Pierre. El problema de la formación del capitalismo in crescimiento e história. Barcelona, Ariel, 1965, p.114.

9 Wallich, Henry. Desenvolvimento periférico, trad. de João Manuel Cardoso de Melo. In: Pereira, Luiz (org.). Subdesenvolvimento e desenvolvimento, op.cit. p. 37-39.

10 Nurkse, Ragnar. Formação e utilização do excedente econômico. Problema operatório fundamental, trad. de Luiz Gonzaga Belluzzo. In: Subdesenvolvimento e desenvolvimento, op. cit., p. 174-177.

11 Galvão, Luís Alfredo. Nacionalismo em sociologia do desenvolvimento, In: Ciências Politicas e Sociais, revista da Escola de Sociologia e Política de São Paulo. São Paulo, v. 11, n. 2, 1973, p. 48-96.

12 Jaguaribe, Hélio. Crisis e alternativas de América Latina: reforma ou revolución. Buenos Aires, Paidos, 1972, p. 48-49.

13 Furtado, Celso. Teoria e politica do desenvolvimento econômico. Apresentação de José Sérgio Rocha de Castro Gonçalves. São Paulo, Abril Cultural, 1983, p. 115,117 e 135 .

14 Merhav, Meir. Dependência tecnológica: monopólio e crescimento. São Paulo, Revista dos Tribunais/Edições Vértice, trad., 1987, p. 18. 
15 Tavares, Maria Conceição. Da substituição de importações ao capital financeiro, $2^{\text {a }}$ ed. Rio de Janeiro, Zahar, 1973, p. 21-22.

$16 \mathrm{Na}$ ampla bibliografia acerca do tema mencionem-se, dentre outros autores ligados ou não à Cepal, Theotônio dos Santos, Cardoso \& Faletto, Vânia Bambirri, Rui Mauro Marini e Jorge Graciarena.

RESUMO - A DENOMINADA TEORIA da dependência é observada sob os aspectos político e de economia política, tendo em vista impugná-la como proposta teórica em si mesma, dada a ausência de elementos metodológicos significativos e de conteúdo inovador. A idéia de que existe dependência é simplesmente tautológica. A rigor, não existe teoria da dependência, mas simplesmente a dependência como processo histórico dentro do sistema internacional de relações de força e poder. Os debates acadêmicos na Cepal trataram do desenvolvimento capitalista na periferia, mais precisamente das conseqüências do capitalismo central na América Latina, capítulo das interpretações relacionadas com o desenvolvimento/subdesenvolvimento, envolvendo o papel dos denominados agentes históricos nas mudanças sociais. O reducionismo dos colecionadores de borboletas nas ciências sociais, ao buscar uma tipologia de dependência, não cria teorias novas, senão generalidades ambíguas.

ABSTRACT - THE SO-CALLED DEPENDENCE theory is here scrutinized in its political aspects and as political economy, with the purpose of opposing it as a theory in itself, once it does not present methodological elements either significant or innovating in their content. The notion that dependence exists is tautological. Strictly speaking, there is no dependence theory, but merely dependence as a historical process within the international system of force and power relationships. The Cepal academy debates have dealt with the capitalist development at the periphery, more precisely with the consequences of central capitalism in Latin America, a chapter on the interpretations related to the development/ underdevelopment condition, which involves the role played by the so-called historical agents in social changes. In their search for a dependence typology, the oversimplication of the butterfly collectors in social sciences does not create a new theory, but merely ambiguous general principles.

Luiz Toledo Machado doutorou-se em Letras (Literatura Brasileira) pela Faculdade de Filosofia, Letras e Ciências Humanas da USP e em Ciências Sociais (Ciência Política) pela Escola de Sociologia e Política de São Paulo. É autor de Conceito de nacionalismo e Formação do Brasil e unidade nacional, entre outros livros. 